\title{
Preferences and Perceptions of Generation Y Sport Students towards the Leadership Behaviour of Coaches
}

\author{
Christopher May \\ School of Economic Sciences, North-West University, Vanderbijlpark, South Africa \\ Christopher.May@nwu.ac.za \\ Bianca Els \\ School of Economic Sciences, North-West University, Vanderbijlpark, South Africa \\ Bianca.Els@nwu.ac.za \\ Peet Viljoen \\ School of Economic Sciences, North-West University, Vanderbijpark, South Africa \\ Peet.Viljoen.@nwu.ac.za
}

\section{Doi:10.5901/mjss.2014.v5n21p61}

\section{Abstract}

Congruence of the leadership behaviour of a coach and the preferred coach leadership behaviour of the athlete is of utmost importance for the continued relationship between the coach and athlete, as well as the ultimate success of the athlete. This study investigated the preferences and perceptions of Generation Y sport students towards the leadership behaviour of their coaches. The sport leadership scale of Chelladurai and Saleh (1980), which consists of five dimensions of leadership attributes, was used to conduct the study. A convenience sampling method was used to collect the data from the Generation $Y$ sport students. Paired samples t-tests were conducted between the grouped dimensions of preferences and perceptions. The results indicated that Generation Y sport students would prefer, for example, to be provided with more training and advice, a more democratic approach by the coach, and that the coach should provide more social support and positive feedback. Analysis of variance (ANOVA) was conducted to determine if perceptions and preferences of sport students regarding the leadership behaviour of coaches differed across the different sport codes. Limited differences were found. Overall, an instrument like this can be used by coaches to improve their coaching behaviour, if found necessary.

Keywords: Leadership; preferences; perceptions; sport; Generation Y

\section{Introduction}

The development and academic interest in leadership theory can be traced back to the $19^{\text {th }}$ century, when Thomas Carlyle introduced his theory of the Great Man in 1840 (Judge, llies, Bono \& Gerhardt, 2002). Harter (2003) highlights that leadership studies do not really go beyond the $19^{\text {th }}$ century. The interest in leadership studies cuts across different disciplines, for example, like in healthcare, religion, non-profit organisations, business and in sports (Grandy \& Holton, 2013; Grandy, 2013; McMurray, Islam, Sarros \& Pirola-Merlo, 2012; Lynman \& Chermack, 2006, \& Mousavi \& Meshkini). The research on leadership in sport has gained momentum, especially from 1980 when Chelladurai and Saleh (1980) published their article on "Dimensions of Leader Behavior in Sports: Development of a Leadership Scale". Before 1980 most of the leadership research in sport was mainly based on management theory and models (Chelladurai \& Saleh 1980).

\section{Background}

The compatibility of the perceptions of coach leadership behaviour and that preferred by athletes is crucial in terms of the relationships between coaches and athletes. The interplay of leadership style is therefore very important. Bennis and Thomas give (2002) this perspective of leadership, "Everyone is tested by life, but only a few extract strength and wisdom from their most trying experiences. They're the ones we call leaders". Bahrami, Zardoshtian and Jourkesh (2011) state 
that a coach or leader should be considered as a full supplement/supportive factor, and not a disciplinarian or dictator. In other words, a coach should be one who plays the role of a facilitator. A successful coach must be flexible in his/her leadership. However, coaches are different with respect to their personality and leadership behaviours, but they have an effect on their players' physical and mental responses (Bahrami et al., 2011). Moreover, coaches are effective agents in their players' activity, enjoyment, resignation, motivation and self-confidence. Some studies apply the term "coach" and "leadership" interchangeably.

McCormack (2007) states that the most crucial factor of a coach's success is that he/she can assist athletes to develop their skills with high-level efficiencies. It is necessary for a coach to recognise athletes' mental and psychic features which impact on their performances. This behaviour has a better effect on the athlete's success in the sport field (Meer \& Rosen, 2008). Meer and Rosen (2008) further state that efficient coaches are those who are familiar with the psychological and sociological issues of the athletes' as well. In other words, coaches do not only care about sport skills, but also consider mental and other skills such as leadership and people skills (Meer \& Rosen, 2008). One of the important challenges of a coach is to keep the athletes motivated all the time. To keep athletes motivated, good leadership is necessary. Vallerand (2004) is of the opinion that a coach cannot motivate athletes while there is a lack of leadership in his/her coaching style. However, what the athlete prefers may not work towards the desired outcome. A case in point to illustrate this; a study has been conducted in the Philippines among dancing students and it was found that an autocratic coaching style is better than a participative style in increasing dance performance (Castillo, Balibay, Alarcon, Picar, Lampitoc, Baylon \& Espinosa (2014).

This study focused on Chelladurai and Saleh's (1980) leadership scale for sports (LSS) in determining the perceptions and preferences of Generation Y sport students regarding the leadership behaviour of their coaches. The use of the Chelladurai and Saleh (1980) scale became quite popular and a number of studies were replicated using the LSS. Many of the studies emphasised different aspects of leadership using the LSS (Chelladurai \& Saleh, 1980). Some researchers focussed on the leadership perceptions' dimension, for example, with regard to its relationship with team success, team cohesion and skill development (Lovelin \& Hanold, 2014; Crăciun \& Rus, 2009; Alfermann, Lee \& Würth, 2005) while others concentrated on the leadership preferences' dimension, for example, with regard to its relationship with athletes' satisfaction, motivation and leadership styles (Bassa, 2012; Surujlal \& Dhurup, 2012; Nazarudin, Fauzee, Jamalis, Geok \& Din; 2009; Singh \& Surujlal, 2006). Chelladurai and Saleh (1980) looked at both preferences and perceptions of the leadership behaviour of coaches. Many of the studies before 1980 mainly used management/business leadership scales to determine the leadership style and traits of coaches. Chelladurai (1984) also introduced the concept of discrepancy between preferences and perceptions of leadership behaviour and satisfaction of athletes. An interesting finding of this study was that training and instruction and positive feedback were the most common dimensions of leader behaviour affecting the athletes' satisfaction.

The LSS (Chelladurai \& Saleh, 1980) concentrated on five preference and perception dimensions, namely, training and instruction (13 items), democratic behaviour (9 items), autocratic behaviour ( 5 items), social support (8 items) and positive feedback ( 5 items). The dimensions are explained as follows: The training and instruction dimension is one of the important functions of the coach as to improve the performance level of the athlete. This dimension addresses the instruction of the coach to assist athletes in reaching their maximum physical potential in acquiring the necessary skills. The democratic and autocratic behaviour of coaches are indications as to what extent the athlete is allowed to make his or her own decisions. The authors highlight that the distinction between democratic and autocratic behaviour is consistent with that in organisational behaviour research. The social support dimension is about how the coach is involved in satisfying the interpersonal needs of the athletes. The positive feedback dimension is about whether the coach gives positive feedback regarding the achievements of athletes.

\section{Purpose of the Study}

The purpose of the study was to determine the preferences and perceptions of Generation $Y$ sport students towards the leadership behaviour of coaches.

\section{Methodology}

A quantitative approach was used in this study. The data were collected by using a non-probability convenience sampling procedure. 


\subsection{Sample}

The sample for the study was Generation Y sport students of different sport codes from a South African higher education institution. The sample size was 161 sport students.

\subsection{Instrument and procedure}

Chelladurai and Saleh's (1980) LSS, a 40-item instrument on leadership perceptions and preferences, was used to collect data for the study. Items in the scale were scored on a 5-point Likert scale, $1=$ never, $2=$ seldom, $3=$ occasionally, $4=$ often and $5=$ always. To assist the respondents in providing more "accurate" responses, seldom was also labelled as " $25 \%$ of the time", occasionally as "about $50 \%$ of the time" and often as "about $75 \%$ of the time". An additional section requesting the demographic information from participants was added to the questionnaire. Sport management lecturers were requested to administer the questionnaire to their students immediately after their lectures. Ethical clearance was given by the institution concerned to conduct the study among sport students and the students were under no obligation to participate in the study. It was also conveyed to them that the confidentiality of students will be protected.

\section{Data Analysis}

The Statistical Package for Social Sciences (IBM SPSS 22) was used for the data analysis. Reliability tests were conducted to measure the internal reliability of the scales of the questionnaire. Frequency tables were used to report on the demographic data. Paired sample t-tests were conducted to identify any significant differences between the perceptions and preferences of students regarding the leadership behaviour of their coaches. Analysis of variance (ANOVA) was conducted to determine if perceptions and preferences of students regarding the leadership behaviour of coaches differed across the different sport codes.

\section{Results}

\subsection{Demographics}

The demographic information is provided in Table 1 . Males constituted $54 \%$ of the sample and females $46 \%$. The sample distribution consisted of $75 \%$ Black and $25 \%$ White students. Most of the student respondents played soccer, namely, 60 (36\%).

Table 1: Demographic Information of Generation Y Sport Students

\begin{tabular}{|llcc|}
\hline Variable & Categor-ies & Count & $\%$ \\
\hline Gender & Male & 89 & 54 \\
& Female & 77 & 46 \\
Race & Black & 124 & 75 \\
& White & 42 & 25 \\
Sport & Rugby & 21 & 13 \\
& Soccer & 60 & 36 \\
& Netball & 32 & 19 \\
& Athletics & 13 & 8 \\
& Hockey & 17 & 10 \\
& Other & 23 & 14 \\
& & & \\
\hline
\end{tabular}

\subsection{The internal reliability values of the perception and preference scales}

The questionnaire was subjected to reliability testing. The overall perception scale and preference scale had Cronbach alpha values of .91 and .89 respectively, which were well above the cut-off point of .70 as suggested by Nunnally and Bernstein (1994). The Cronbach alpha values for the subscales values are provided in Table 2, which are all above .70. 


\subsection{Perceptions and preferences of sport students of different sport codes}

The perceptions and preferences of sport students of different sport codes are presented in Table 3. The "other" group are students who participated in other sport codes, for example, such as table tennis and rowing. The athletics group had the highest mean values for all the perception dimensions regarding their coaches, except for the autocratic behaviour dimension. The training and instruction and the positive feedback dimensions had high preference mean values. Similar findings with regard to the training and instruction dimension were reported in other studies and this dimension is therefore very important to athletes (Chelladurai, 1984; Terry, 1984).

Table 2: Reliability Values of Subscales

\begin{tabular}{|lccc|}
\hline Dimension & Number & Cronbach aplha values for Perceptions & Cronbach alpha values for Preferences \\
\hline Training and instruction & 13 & .88 & .87 \\
Democratic behaviour & 9 & .87 & .83 \\
Autocratic behaviour & 5 & .79 & .85 \\
Social support & 8 & .84 & .86 \\
Positive feedback & 5 & .78 & .83 \\
\hline
\end{tabular}

Table 3: Perceptions and Preferences of Sport Students of Different Sport Codes

\begin{tabular}{|c|c|c|c|c|c|}
\hline Training and instruction & Mean Perc* & Mean Pref** & Democratic behaviour & Mean Perc & Mean Pref \\
\hline Rugby & 3.95 & 4.12 & Rugby & 3.14 & 3.60 \\
\hline Soccer & 3.91 & 4.26 & Soccer & 3.11 & 3.72 \\
\hline Netball & 3.71 & 4.43 & Netball & 3.16 & 3.83 \\
\hline Athletics & 4.13 & 4.29 & Athletics & 3.83 & 3.96 \\
\hline Hockey & 4.02 & 4.28 & Hockey & 3.71 & 3.75 \\
\hline Other & 3.87 & 4.33 & Other & 3.04 & 3.91 \\
\hline Autocratic behaviour & Mean Perc & Mean Pref & Social behaviour & Mean Perc & Mean Pref \\
\hline Rugby & 2.66 & 2.29 & Rugby & 2.97 & 3.13 \\
\hline Soccer & 2.64 & 2.87 & Soccer & 3.14 & 3.43 \\
\hline Netball & 2.92 & 2.54 & Netball & 3.28 & 3.28 \\
\hline Athletics & 2.76 & 3.38 & Athletics & 3.61 & 3.61 \\
\hline Hockey & 2.76 & 2.58 & Hockey & 3.19 & 3.19 \\
\hline Other & 2.62 & 2.23 & Other & 3.13 & 3.13 \\
\hline Positive feedback & Mean Perc & Mean Pref & & & \\
\hline Rugby & 3.89 & 4.24 & & & \\
\hline Soccer & 4.04 & 4.23 & & & \\
\hline Netball & 4.04 & 4.50 & & & \\
\hline Athletics & 4.03 & 4.53 & & & \\
\hline Hockey & 4.28 & 4.33 & & & \\
\hline Other & 4.06 & 4.47 & & & \\
\hline
\end{tabular}

In this study all the mean preference values were greater than the mean perception values, except for hockey and netball on the autocratic behaviour dimension. Female students therefore had a lower preference for an autocratic leadership style.

\subsection{Differences between the grouped dimensions of leadership behaviour}

Paired samples t-tests were conducted between the grouped dimensions of perceptions and preferences (being all sport codes combined in terms of preferences and perceptions) of sport students regarding the leadership behaviour of coaches. Table 4 shows that the autocratic behaviour dimension was the only dimension with an insignificant difference; all the other dimensions had significant differences. All the mean values of the perceptions of sport students were lower than the preferences of sport students regarding the leadership behaviour of coaches, as illustrated in Table 4 . What this translates into are that athletes would prefer to be provided with more training and instruction, that the coach should be more democratic in his/her approach, that the coach should provide more social support and positive feedback. With 
regard to autocratic behaviour, the coaches "met" the preferences of the sport students. The grouped mean values of the positive feedback subscale for both the perception and preference scales were the highest, that of 4.05 and 4.35 respectively. The grouped mean values of the autocratic behaviour subscales were the lowest, which bodes well for the coaches in terms of their democratic leadership behaviour.

Table 4: Differences between Grouped Mean Values of the Dimensions

\begin{tabular}{|c|c|c|c|}
\hline Paired samples t-test & Mean & Std. Dev. & Sig. (2-tailed) \\
\hline Pair 1: Perceptions - Training and instructions & 3.90 & .5855 & \multirow{2}{*}{$.000^{*}$} \\
\hline Preferences - Training and instructions & 4.29 & .5240 & \\
\hline Pair 2: Perceptions - Democratic behaviour & 3.31 & .7966 & \multirow{2}{*}{$.000^{*}$} \\
\hline Preferences - Democratic behaviour & 3.82 & .6079 & \\
\hline Pair 3: Perceptions - Autocratic behaviour & 2.67 & .8762 & \multirow{2}{*}{.730} \\
\hline Preferences - Autocratic behaviour & 2.70 & 1.0537 & \\
\hline Pair 4: Perceptions - Social support & 3.07 & .8035 & \multirow{2}{*}{$.001^{*}$} \\
\hline Preferences - Social support & 3.31 & .8755 & \\
\hline Pair 5: Perceptions - Positive feedback & 4.05 & .7341 & \multirow{2}{*}{$.000^{*}$} \\
\hline Preferences - Positive feedback & 4.35 & .6550 & \\
\hline
\end{tabular}

*Significant $(p<.05)$

The ANOVA results of the differences of the grouped perceptions of all the sport students of the different sport codes are provided in Table 5. The democratic behaviour dimension had a significant difference caused by a significance difference between the athletics and soccer student groups. The multiple comparison table of the Tukey post-hoc test (table not provided) indicated that the perceptions of the soccer and athletics sport students differed significantly with regard to the democratic behaviour dimension. All the mean values of the athletics student sport group had higher mean values on the democratic behaviour dimension compared to the soccer sport student group. This indicates that the athletics sport student group perceived their coaches to be more democratic than that of the soccer sport student group. The ANOVA results of the differences of the grouped preferences of all the sport students of the different sport codes are provided in Table 6 . The autocratic behaviour was the only one with a significant difference. This was caused by a significant difference between the athletics sport student group and the "other" sport student group. The multiple comparison table of the Tukey post-hoc test (table not provided) indicated that the preferences of the athletics sport student group differed significantly with that of the "other" sport student group on the autocratic dimension. The athletic sport student group preferred their coaches to be more autocratic compared to the "other" sport student group.

Table 5: ANOVA Results of Differences of the Grouped Perceptions of Athletes of the Different Sport Codes

\begin{tabular}{|l|cc|}
\hline Dimension & F-value & Sig \\
\hline Training and instruction & 1.072 & .378 \\
Democratic behaviour & 3.171 & $.009^{*}$ \\
Autocratic behaviour & 0.283 & .922 \\
Social support & 1.941 & .090 \\
Positive feedback & 0.546 & .741 \\
\hline
\end{tabular}

*Significant $(p<.05)$

Table 6: ANOVA Results of Differences of the Grouped Preferences of Athletes of the Different Sport Codes

\begin{tabular}{|l|cl|}
\hline Dimension & F-value & Sig \\
\hline Training and instruction & 0.869 & .503 \\
Democratic behaviour & 0.997 & .421 \\
Autocratic behaviour & 2.674 & $.024^{\star}$ \\
Social support & 0.967 & .440 \\
Positive feedback & 1.197 & .313 \\
\hline
\end{tabular}

*Significant $(p<.05)$ 


\subsection{A comparison of an earlier study by Surujlal and Dhurup (2012) conducted in South Africa}

The results of a comparative study conducted among South African students by Surujlal and Dhurup (2012) in a context similar to this study are provided in Table 7. There were some differences between this study and that of Surujlal and Dhurup (2012) with regard to the mean and standard deviation values. It is important to note that the mean values of the study of Surujlal and Dhurup had to be reversed scored for comparison purposes. If one, for example, just had to compare the preferred social support behaviour of the coaches by students, then the mean value of this study is much in line with the study of Surujlal and Dhurup (2012), for example, on the social support dimension the mean value for this study was 3.31 and for the study of Surujlal and Dhurup (2012) it was 3.47. This translates into that the students in the case of the Surujlal and Dhurup (2012) study had a higher preference score for social support from their coaches.

Table 7: Comparison of Means and Standard Deviations of the Preference Scale of this Study with that of Surujlal and Dhurup (2012)

\begin{tabular}{|c|c|c|c|}
\hline Dimension & Number of Respondents & Mean (Preferences) & Standard Deviation \\
\hline \multicolumn{4}{|l|}{ Training and instruction } \\
\hline This study & 166 & 4.29 & .52 \\
\hline Surujlal and Dhurup & 220 & $3.89^{*}$ & .69 \\
\hline \multicolumn{4}{|l|}{ Democratic behaviour } \\
\hline This study & 166 & 3.82 & .61 \\
\hline Surujlal and Dhurup & 220 & 3.54 & .69 \\
\hline \multicolumn{4}{|l|}{ Autocratic behaviour } \\
\hline This study & 166 & 2.70 & 1.05 \\
\hline Surujlal and Dhurup & 220 & 3.09 & .75 \\
\hline \multicolumn{4}{|l|}{ Social support } \\
\hline This study & 166 & 3.31 & .88 \\
\hline Surujlal and Dhurup & 220 & 3.46 & .66 \\
\hline \multicolumn{4}{|l|}{ Positive feedback } \\
\hline This study & 166 & 4.35 & .66 \\
\hline Surujlal and Dhurup & 220 & 4.02 & .83 \\
\hline
\end{tabular}

*The legend used by Surujlal and Dhurup was 1=always and 5=never

This study used the opposite $1=$ never and $5=$ =always

\section{Discussion}

This study investigated the perceptions and preferences of sport students towards the leadership behaviour of coaches. For all the sport codes and the five dimensions it was found that the coach could do more, except for the autocratic behaviour dimension. In other words, the sport students expected that the coaches could do more in providing training and instruction, could be more democratic and social involved in his/her behaviour, could provide more feedback and could be less autocratic. Positive feedback was regarded as the most important in terms of the preferred coaching behaviour. This was a similar result of the study of Surujlal \& Dhurup (2012). Findings will differ given differences with regard to, for example, the political conditions and cultural background of both the coach and athlete (Mji \& Surujlal, 2013; Weiss \& Ferrer-Caja, 2002), for example, Mji and Surujlal (2013) compared student-athlete preferences towards couching behaviour between India and South Africa and found differences which they argued were for reasons such as, for example, social and political factors. In this study there were no significant differences between athletics as a more individual sport, compared to all the other team sports. One of the challenges in team coaching is to achieve cohesion among players (Ramzaninezhad \& Keshtan, 2009); where in the case of athletes the attention is more on the individual. The training and instruction dimension is very important in terms of the athletes and coach relationships, as this is one of the key aspects to superior performance of the athletes. However, the group difference of perceptions and preferences was significant in respect of training and instruction - see Table 4. The sport students expected more in terms of the training and instruction dimension. The coaches' leadership behaviour has been seen as too autocratic. But in many of the sport codes this seems to be the best or appropriate style to achieve desired outcomes (Castillo, Balibay, Alarcon, Picar, Lampitoc, Baylon \& Espinosa, 2014). 


\section{Limitations and Implications for Further Study}

The study did not address the issue of the level of satisfaction the student experienced or is currently experiencing from the leadership coaching behaviour of the coach. This is important to address in future studies. The sample was drawn from one higher education institution and the results cannot be generalised to other higher education institutions.

\section{Conclusion}

Sport coaches should have an informed idea of the perceptions and preferences of their sport students regarding their leadership and coaching behaviour or styles. Furthermore, they need to understand whether their leadership behaviour is appropriate to their particular sport code as to have a better relationship with their sport students. Some athletes have a preference for a particular leadership style and this can impact on the athlete's motivation and performance. There should be a match between the coach's leadership style and what is being preferred by the athletes so that the outcomes will be positive. However, this may not always be the case and the student athlete needs to be informed what to expect. It is important that coaches need to get feedback from athletes as to how these athletes perceive their leadership style, for example, is it viewed in a positive or negative light? There should also be an understanding of the kind of relationship that is acceptable and beneficial to both the coach and the athlete.

\section{References}

Alfermann, D., Lee, M. \& Würth, S. (2005). Perceived leadership behaviour and motivational climate as antecedents of adolescent athletes' skill development. Athlete Insight: The Online Journal of Sport Psychology, 7(2), 14-36.

Bahrami, S., Zardoshtian, S. \& Jourkesh, M. (2011). The effect of leadership on the motivation and satisfaction of Iranian women premier basketball league. Annals of Biological Research, 2(4), 321-329.

Bassa, M. (2012). Soccer coaching leadership styles and athletes satisfaction: review of literature. International Journal of Social Sciences and Interdisciplinary Research, 1(6), 10-20.

Bennis, W. \& Thomas, R. (2002). Crucibles of Leadership. Harvard Business Review. September, 1-8.

Castillo, D., Balibay, M., Alarcon, J., Picar, J., Lampitoc, R., Baylon, M. \& Espinosa, A. (2014). Autocratic and Participative Coaching Styles and Its Effects on Students' Dance Performance. International Journal of Learning, Teaching and Educational Research, 3(1), 32-44.

Chelladurai, P. (1984). Discrepancy between Preferences and Perceptions of Leadership Behaviour and Satisfaction of Athletes in Varying Sports. Journal of Sport Psychology, 6, 27-41.

Chelladurai. P. \& Saleh, S. (1980). Dimensions of leader behavior in sports: Development of a leadership scale. Journal of Sport Psychology, 2, 34-45.

Crăciun, M. \& Rus, C. (2009). The relationship between perceived coach leadership behaviours and team cohesion among Romanian athletes. Revista Iberoamericana de Psicologia del Ejercicio y el Delporte, 4(2), 217-231.

Grandy, G. (2013). An exploratory study of strategic leadership in churches. Leadership \& Organization Development Journal, 34(7), 616-638.

Grandy, G. \& Holton, J. (2013). Leadership development needs assessment in healthcare: a collaborative approach. Leadership \& Organization Development Journal, 34(5), 427-445.

Harter, N. (2003). Between Great Men and Leadership: William James on the Importance of Individuals. Journal of Leadership Education, 2(1), 3-12.

Judge, T., llies, R., Bono, J. \& Gerhardt, M. (2002). Personality and Leadership: A Qualitative and Quantitative Review. Journal of Applied Psychology, 87(4), 765-780.

Lynham, S. \& Chermack, T. (2006). Responsible Leadership for Performance: A Theoretical Model and Hypothesis. Journal of Leadership \& Organizational Studies, 12(4), 73-88.

Lovelin, M. \& Hanold, M. (2014). Female Sport Leaders' Perceptions of Leadership and Management: Skills and Attitudes and Success. Global Sport Business Journal, 2(1), 14-29.

McCormack, P. (2007). A Study of the Leadership and Coaching Behaviours of High Level Hurling Coaches. (Master's thesis). Waterford Institute of Technology.

McMurray, A., Islam, M., Sarros, J. \& Pirola-Merlo, A. The impact of leadership on workplace climate and performance in a non-profit organization. Leadership \& Organization Development Journal, 33(6), 522-549.

Meer, J. \& Rosen, H. (2008). The Impact of Athletic Performance on Alumni Giving: An Analysis of Micro Data. CEPS Working Paper No. 162.

Mji, A. \& Surujlal, J. (2013). Leadership Behaviour of Student-Athletes: A Comparative Study of South Africa and India. Mediterranean Journal of Social Sciences, 4(11), 81-9.

Mousavi, S. \& Meshkini, A. (2011). The Relationship between Coaches' Leadership Behaviour with the Athletes' Sex and Age. International Journal of Academic Research in Business and Social Science, 1(3), 337-341. 
Nazarudin, M., Fauzee, M., Jamalis, M., Geok, S., \& Din, A. (2009). Coaches' leadership styles athlete satisfactions among Malaysian university basketball team. Research Journal of International Studies, Issue 9, 4-11.

Nunnally, J. \& Bernstein, I. (1994). Psychometric Theory (3rd ed.) New York: McGraw-Hill.

Ramzaninezhad, R \& Keshtan, M. (2009). The Relationship Between Coach's Leadership Styles and Team Cohesion in Iran Football Clubs Professional League. Brazilian Journal of Biomotricity, 3(2), 111-120.

Singh, P. \& Surujlal, J (2006). Athlete satisfaction at universities in Gauteng. South African Journal for Research in Sport, Physical Education and Recreation, 28(2), 121-131.

Surujlal, J. \& Dhurup, M. (2012). Athlete preferences of coach's leadership style. African Journal for Physical, Health Education, Recreation and Dance, 18, 112-113.

Terry, P. (1984). The Coaching Preferences of Elite Athletes Competing at Universiade '83.

Canadian Journal of Applied Sport Sciences, 9(4), 201-208.

Vallerand, R. (2004). Intrinsic and Extrinsic Motivation in Sport. Encyclopaedia of Applied Psychology, 2, 427-435.

Weiss, M. \& Ferrer-Caja, E. (2002). Motivational Orientation and Sport Behavior. In T. Horn (Ed.), Advances in Sport Psychology (2nd ed., pp. 101-183). Champaign. Human Kinetics Publishers, Inc. 